\title{
EDIÇÕES FAC-SIMILAR, SEMIDIPLOMÁTICA E ESTUDO GRAFEMÁTICO DE UM PROCESSO CRIME DE HOMICÍDIO DE 1909
}

\author{
$\underline{\text { Gracília Pereira Santos }}{ }^{1}$; Josenilce Rodrigues de Oliveira Barreto ${ }^{2}$
}

\author{
1. Bolsista voluntária - PEVIC, Graduanda em Licenciatura Letras com Francês, Universidade Estadual de Feira de Santana, \\ e-mail:graciliap@gmail.com \\ 2. Orientadora, Departamento de Letras e Artes, Universidade Estadual de Feira de Santana, \\ e-mail: nilce11.barreto@gmail.com
}

PALAVRAS-CHAVE: Filologia; Edições filológicas; Processo Crime de Homicídio; Estudo grafemático.

\section{INTRODUÇÃO}

A princípio, a Filologia firmava-se apenas na ecdótica, entretanto, com o decorrer do tempo, seus estudos foram ampliados, sendo introduzidos no seu campo de pesquisa a arte, a cultura e a língua de um povo através de textos escritos, pois seu foco é editar, a partir de critérios específicos, textos acerca das sociedades. Posteriormente, ela foi dividida em dois aspectos: a Linguística, que também faz estudos comparativos da língua, visto que a mesma tem um significado muito importante para uma sociedade; e a Filologia Textual, que tem como finalidade a preservação de textos e, através disso, pode-se fazer um resgate dos documentos do passado que contêm informações históricas, contribuem para o entendimento dos estudos no presente, a partir de documentos impressos e/ou escritos. Com base nessas informações, este trabalho teve como finalidade a edição filológica e a análise grafemática constante em um Processo Crime de Homicídio de 1909, ocorrido no distrito de Humildes BA, visando a compreensão do seu contexto histórico, a partir de sua descrição e transcrição e respeitando à grafia presente no documento original. Através disso, foi possível analisar a mudança ortográfica presente no documento, buscando-se, assim, fazer, posteriormente, um estudo comparativo. Ao editar o documento foi possível obter dados gerais que serão apresentados, já que são de suma importância as informações, que abrangem apontamentos culturais e sociais, contidas no documento.

\section{METODOLOGIA}

Para a realização desta pesquisa documental, baseamo-nos nos critérios de edição adotados por Queiroz (2007, p. 34). Assim,

- Para a descrição do documento, observamos as seguintes características:

- Número de colunas;

- Número de linhas da mancha escrita;

-Existência de ornamentos;

-Maiúsculas mais interessantes;

-Existências de sinais especiais;

- Número de abreviaturas;

- Tipo de escrita;

-Tipo de papel.

Já para a transcrição do documento, utilizamos os seguintes critérios:

- Respeitar fielmente o texto: grafia, linhas, fólios, cor da tinta utilizada, etc.;

- Fazer remissão ao número do fólio no ângulo superior direito;

- Numerar o texto linha por linha, constando a numeração de cinco em cinco;

- Separar as palavras unidas e unir as separadas;

- Desdobrar as abreviaturas usando itálico; 
-Utilizar colchetes para as interpolações: [ ];

- Indicar as rasuras, acréscimos e supressões através dos seguintes operadores:

$((\dagger))$ rasura ilegível;

$[\dagger]$ escrito não identificado;

(...) leitura impossível por dano do suporte;

// leitura conjecturada;

$<$ supressão;

( ) rasura ou mancha;

[ ] acréscimo

Após a edição do documento, realizamos o estudo grafemático de algumas palavras presentes no texto.

\section{RESULTADOS E DISCUSSÃO}

Neste trabalho, foi possível a edição filológica de um crime de homicídio, ocorrido no distrito de Humildes - Ba, no ano de 1909. O documento se encontra no CEDOC, localizado na Universidade Estadual de Feira de Santana- BA, sob a estante 05, Caixa 143, documento 2752 e possui 18 folios, escritos no recto e em alguns versos, em papel almaço. O manuscrito discorre sobre um crime e tem como réu Jeronymo de Sousa Almeida, acusado de ter assassinado a vítima Laureano Gonçalves da Costa. Dessa forma, para a análise desse documento, utilizamos a edição fac-similar e semidiplomática, a fim de editá-lo, mantendo-o o mais fiel possível ao original, o que pode ser observado na figura 1. Também foram analisadas quais as mudanças grafemáticas, ocorridas em relação à escrita atual (tabela 1). A primeira coluna da tabela apresenta aalgumas palavras que estão presentes no documento, a segunda coluna, o contexto no qual estão inseridas a terceira coluna exemplifica quais as mudanças ocorridas, e a última coluna, as palavras atuais que correspondem às usadas antigamente. Em vista disso, é possível notar, a seguir, a edição fac-similar e semidiplomática e a variação grafemática do documento.

Figura 1: Edição fac-similar e semidiplomática do fólio $5 \mathrm{v}$ do processo crime de homicídio de 1909

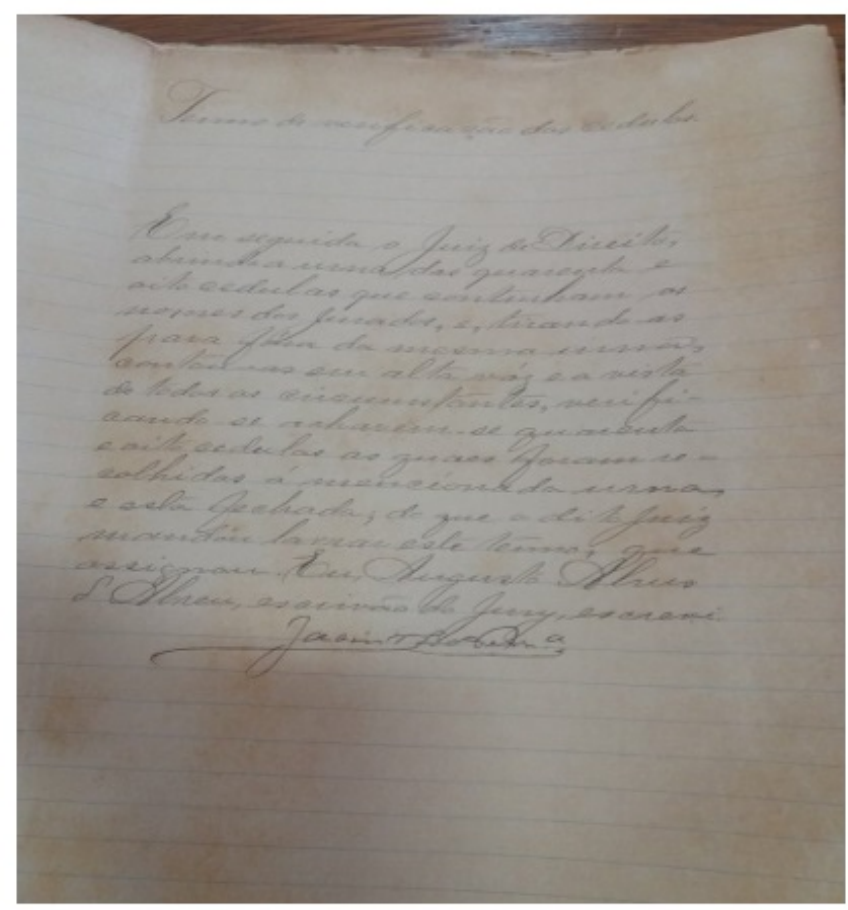

Termo de verificação das cédulas

Em seguida o juiz de direito abrindo a urna das Quarenta e oito cédulas que continham os nomes dos jurados, e, tirando-as para fóra da mesma urna, contou-as em alta vóz e a vista de todos as circuntantes verificando-se acharem-se quarenta e oito cédulas as quaes foram re-

15 colhidas à mencionada urnas e esta fechada de que o dito juiz mandou lavrar este termo, que assignou. Eu, Augusto Abreus 


\begin{tabular}{|c|c|c|c|}
\hline \multicolumn{4}{|c|}{ ESTUDO GRAFEMÁTICO DO DOCUMENTO } \\
\hline $\begin{array}{c}\text { GRAFIA CONSTANTE } \\
\text { NO DOCUMENTO (1909) }\end{array}$ & CONTEXTO & $\begin{array}{c}\text { ANÁLISE } \\
\text { GRAFEMÁTICA }\end{array}$ & $\begin{array}{c}\text { GRAFIA ATUAL } \\
\text { (2017) }\end{array}$ \\
\hline ASSIGNOU & $\begin{array}{lcc}\text { "[...] mandou lavrar } & \text { este } \\
\text { termo, que assignou } & {[\ldots]} \\
\text { (PROCESSO CRIME } & \text { DE } \\
\text { HOMICÍDIO, 1909, f. V) } & \end{array}$ & $\begin{array}{c}\text { Síncope da } \\
\text { consoante sonora } \\
\text { /g/ }\end{array}$ & ASSINOU \\
\hline JURY & $\begin{array}{l}\text { “[...] escrivão do jury, escrevi. } \\
{[\ldots . .] \text { (PROCESSO CRIME DE }} \\
\text { HOMICÍDIO, } 1909, \text { f. V) }\end{array}$ & $\begin{array}{l}\text { Substituição do } \\
\text { grafema /y/ pelo } \\
\text { grafema /i/ }\end{array}$ & JURI \\
\hline RESPONDEO & $\begin{array}{l}\text { "[...] Respondeo chamar-se } \\
\text { José Francisco Sant'Anna [...]" } \\
\text { (PROCESSO CRIME DE } \\
\text { HOMICÍDIO, 1909, f. VI) }\end{array}$ & $\begin{array}{l}\text { Substituição do } \\
\text { grafema /u/ pelo } \\
\text { grafema /o/ }\end{array}$ & RESPONDEU \\
\hline
\end{tabular}

\section{CONSIDERAÇÕES FINAIS}

Em conformidade com este trabalho, foi possível notar claramente a necessidade de pesquisas voltadas para o estudo de documentos do sertão baiano, partindo-se de sua edição e de análises linguísticas variadas desses textos históricos, os quais podem ser documentos que auxiliam na reconstrução da história das sociedades e das línguas. Portanto, através das edições fac-similar e semidiplomática e do estudo grafemático foi possível a realização do estudo e anáise do documento, possibilitando estudar a língua, a cultura e a história de um determinada sociedade e contribuindo com os estudos filológicos para a preservação das informações contidas nos manuscrito, com o propósito de que outros indivíduos da comunidade acadêmica possam ter proximidade com a edição filológica do documento. Em suma, este trabalho teve como finalidade a edição filológica e o seu estudo grafemático de um processo crime de homicídio, ocorrido no distrito de Humildes - BA, em 1909, o qual está no Centro de Documentação e Pesquisa - CEDOC, localizado na Universidade Estadual de Feira de Santana - Ba, tendo como partes a vítima - Jeronymo de Sousa Almeida - e o réu - José Francisco de Sant' Anna.

\section{REFERÊNCIAS}

SANTOS, Rosa Borges dos. A Filologia textual e a gramática estilística do autor. In: TEIXEIRA, Maria da Conceição Reis; Queiroz, Rita de Cássia Ribeiro de; . (Org.).

Diferentes Pespectivas dos estudos filológicos: Salvador: Quarteto, 2006. p. 79 - 92. 
QUEIROZ, Rita de Cássia Ribeiro de. Introdução metodológica. In: (Org.). Documentos do acervo de Monsenhor Galvão: edição semidiplomática. Feira de Santana: Universidade Estadual de Feira de Santana, 2007. p. 23-34.

TEYSSIER, Paul. História da língua portuguesa Tradução de Celso Cunha. São Paulo: Martins Fontes. 1997. 